investigate the aetiology. We agree with $\mathrm{A} \mathrm{F}$ Mellon and colleagues about the usefulness of urine microscopy as an aid to diagnosing infection, but we however advise caution when dealing with children, ' patients with a self induced diuresis, and patients with vaginitis or cervicitis. ${ }^{2}$

Steve Higgins and Eboo Versi preach, wisely, that patients should have other causes of urethral symptoms investigated, and we do not disagree. We, however, took a pragmatic approach, realising that this was probably a low risk population ${ }^{3}$ and that a sexual history could be used as a screening instrument. The definition of the urethral syndrome was one of exclusion and was consistent with the Medical Research Council's definition. ${ }^{4}$ The finding that the urethral syndrome in our patients was negatively correlated with sexual activity reaffirms our belief, and that of others, ${ }^{5}$ that most cases of the urethral syndrome are not related to sexually acquired disease. With regard to nocturia, we defined it as voiding in excess of a patient's normal habit.

Frank Dobbs's comments on the power of the study are interesting. Regrettably, all research is a balance between what is feasible and what is desirable. Given the size of our sample, we did fail to disprove the null hypothesis that there was no difference in psychiatric disease between the two groups. We found that $17 \%(5 / 29)$ of the women with urinary tract infection and $25 \%(10 / 40)$ of those with the urethral syndrome had psychiatric disease. Had 17 (43\%) patients with the urethral syndrome been psychiatrically ill this would have been significant at the $5 \%$ level $\left(\chi^{2}=3 \cdot 84,1 \mathrm{df}\right)$ and the sample size no larger. We had no previous work on which to judge our sample size and must leave it to others to confirm or refute our findings.

We thank Versi for pointing out an error in table I, which gives the mean (SD) dysuria score of patients with the urethral syndrome and urinary tract infection: the correct figures are $4.69(2 \cdot 1)$ and $5 \cdot 27(1 \cdot 8)$, respectively. This difference is not significant.

MICHAEL C KELSEY

Whittington Hospital

London N195NF

Napsbury Hospital,

London Colney,

Hertfordshire AL2 1AA

D SUMNERS

Royal Free Hospital,

I CHAIT

London NW3 2QG

1 Working Group of the Research Unit, Royal College of Physicians. Guidelines for the management of acute urinary tract infection in childhood. $\mathcal{J} R$ Coll Physicians Lond 1991, 25:36-42.

2 Kelsey MC, Fillin B. Gonorrhoea presenting as "sterile" pyuria. BMF 1980;281:1009.

3 Kelsey MC, Mann GK, Bangham AM, Milnthorpe J. Nonspecific (anaerobic) vaginitis: relevance of clinical and
s. specific (anaerobic) vaginitis: relevance of clinical and
laboratory studies in a practice population. $f R$ Coll Gen Pract laboratory studies

4 Members of the Medical Research Council Bacteriuria Committee. Recommended terminology of urinary-tract infection. BMF 1979;i: 717-9.

5 Gillepsie WA, Henderson EP, Linton KB, Smith PJB. Microbiology of the urethral (frequency and dysuria) syndrome. A controlled study with 5 year review. Br $\mathcal{J}$ Urol 1989;64:270-4.

\section{Clinical trials in community pharmacies}

SIR,-Steve Chaplin and Alison Blenkinsopp's editorial on clinical trials in community pharmacies states that great ignorance exists of the use, efficacy, and safety of over the counter medicines. ${ }^{1}$ The profile of safety and efficacy has been well established by the time these drugs are licensed; that the medicine is available without prescription indicates that there were no major fears about safety. We need to learn more about use in the community, but it is incorrect to imply that inadequately researched drugs are available through pharmacies.
The authors state that pharmacy based trials conforming to the European Commission's guidelines for good clinical practice are possible. Compliance with some of the stipulations of the guidelines, however, would be problematic. For example, it is necessary to check case record forms with source documents, such as patients' notes. ${ }^{2}$ This ensures that the record form accurately represents the facts. Unless pharmacists keep separate notes on individual patients such validation would be impossible.

The guidelines state that the investigator is medically responsible for subjects during the trial and must ensure that appropriate medical care is maintained subsequently. Clearly, this cannot apply if the investigator is not medically qualified.

According to the guidelines, investigators should immediately notify the sponsor, and possibly the ethics committee and authorities, of serious adverse events. These include death, life threatening events, and events resulting in admission to hospital, but the pharmacist might not be aware of these if the patient presented to his or her general practitioner or hospital. This affects the validity of any study.

The study that compared astemizole and terfenadine was unsatisfactory in that inappropriate conclusions were drawn. It was claimed that patients' assessments of control of symptoms showed comparability in the onset of action of the two drugs. ${ }^{3}$ It was subsequently pointed out that the study had not been performed in a way that made this inference possible. ${ }^{4}$ The first follow up data were obtained some 11 hours after dosing, which would have failed to detect the actual onset of action of the drugs (expected after about one hour with terfenadine)

Though we do not deny that community pharmacists could have a valuable role in clinical research, the process may not be straightforward and, for the present, the proposition should be viewed with caution.

H C MASHETER

E G BROWN

Marion Merrell Dow,

Uxbridge,

Middlesex UB 11 1BE

1 Chaplin S, Blenkinsopp A. Clinical trials in community pharmacies. BMF 1991;304:63-4. (11 January.)

2 Committee for Proprietary Medicinal Products Working Party on Efficacy of Medicinal Products. Good clinical practice for trials on medicinal products in the European Community. Brussels: Commission of the European Communities, 1988. (No 111/3976/88-EN Final.)

3 Quick JM, Blenkinsopp A. A community pharmacy study to compare the control of hay fever symptoms by astemizol $10 \mathrm{mg}$ and terfenadine $120 \mathrm{mg}$. Pharmaceutical foumal 1991;246:272-5.

4 Masheter HC. Control of hay fever symptoms. Pharmaceutical fournal 1991;246:410.

\section{Apnoea monitors and accidental strangulation}

SIR, - J L Emery and colleagues draw attention to the risk of accidental strangulation associated with apnoea monitors, referring to an event that occurred when a Graseby MR 10 monitor was used. ${ }^{\prime}$

I wish to point out that every monitor leaves Graseby Medical's factory with an instruction leaflet. This leaflet explains where to position the sensor and that the tubing should be brought down the baby's legs, preferably underneath the clothing, so that accidental strangulation is not possible. Also, every respiration sensor comes in a pouch bearing an explanatory diagram.

As the company is aware that these issues cannot be emphasised enough it is currently reviewing the packaging of the sensor. Explanatory text will be added in six languages, as well as a different and clearer diagram. Thus every time a new sensor is used both the diagram and the instructions can be referred to, giving optimal and instantaneous information.

When these sensors and monitors go to the community it is paramount that those who hand them out fully educate the users in their use. These moves should prevent further events similar to that reported by Emery and colleagues.

JASPERIEN MEINHARDT

Graseby Medical,

Watford,

Hertfordshire WD2 4LG

1 Emery JL, Taylor EM, Carpenter RG, Waite AJ. Apnoea monitors and accidental strangulation. BMJ 1992;304:117. (11 January.)

\section{Not Anon}

SIR,-In The Penguin Book of Comic and Curious Verse, published in 1952, J M Cohen, who had selected the verses, expressed his debt of gratitude to W H Auden for supplying the verse "The Common Cormorant."2-4 Cohen noted in the foreword to the book that he had always suspected it to be a composition of Auden's "fathered by him on that broad shouldered old reprobate, Anon," whose authorship it was published under.

JIM MCCRACKEN

Surgery on Rise Park,
Nottingham NG5 5EB

1 Cohen JM, ed. The Penguin book of comic and curious verse. Harmondsworth: Pengiun, 1952:10.

2 Smith T. On lightning. $B M \mathcal{F}$ 1991;303:1563. (21-28 December.) 3 Isherwood C. The common cormorant. In: Grigson G, ed. Faber book of nonsense verse. London: Faber, 1979:292.

4 Gordon R. Not Anon. BMF 1992;304:257. (25 January.)

\section{Junior doctors on the warpath}

SIR, - Though I can understand the frustration of junior doctors that led to the call for a ballot on industrial action, I think that they will find that it was an ill judged decision which they will come to regret. Be that as it may, I cannot understand how the $B M \mathcal{F}$, which has such scrupulously high standards for publishing scientific articles, could accept Luisa Dillner's editorial discussing the issue,' which is inaccurate, misleading, and, I believe, irresponsible.

To say that "in 12 months little or nothing has changed" is flying in the face of the facts. In my own region of Wessex 201 posts were identified last year where junior doctors were working in excess of 83 hours a week in hard pressed specialties. A star chamber meeting between the regional task force and local working parties was held in November, and as a result of action after that meeting there are currently 80 posts that require in excess of 83 hours, but measures identified within each unit will reduce this number during 1992 to about seven. The regional task force will now be concentrating on those posts requiring over 73 hours.

To accuse some of the task forces of "incompetence" is both insulting and demoralising. Of course, some have been more effective than others. It is for this reason that a national meeting of the chairmen of regional task forces is to be held shortly so that best practice can be disseminated widely.

I suggest that the progress that those of us who were party to the agreement to reduce junior doctors' hours of work wish to see is more likely to follow regular factual reports than ill informed editorials.

A P J ROSS

Chairman, Joint Consultants Committee,

London WCIH 9JP

1 Dillner L. Junior doctors on the warpath. BMf 1992;304:270. (1 February.) 